\title{
入出力数が異なるシステムに対する最適追従制御*
}

論 文

\author{
池田雅 ** $^{* *}$ 榎木圭一 ${ }^{* * *}$ ・藤 崎泰 正 $^{* *}$
}

\section{Optimal Tracking Control of Nonsquare Systems*}

Masao IkedA ${ }^{* *}$, Keiichi Enoki ${ }^{* * *}$ and Yasumasa FuJisAki ${ }^{* *}$

\begin{abstract}
For nonsquare plants, we propose a method for designing optimal tracking and servo systems based on quadratic performance indices. It is assumed that the number of inputs of the plant is greater than that of outputs. In this case, the steady-state input achieving a specified reference signal at the output is not unique. We utilize this freedom to improve the transient behavior of tracking. The optimal control laws are composed of state feedback with an optimal regulator gain, feedforward of the reference signal, and a constant term determined by the initial state of the system. The constant term is not needed if we assume that the change of the reference signal occurs only when the plant is in a steady state.
\end{abstract}

\section{1. はじめに}

本論文では，ステップ関数を参照信号として，最適レ ギュレータ理論を応用した最適追従系や最適サーボ系の 設計を考える†。乙れまで，乙の問題はほとんど制御対 象の入出力数が同じ場合について考えられてきた．入出 力数が異なる場合のうち, 入力数が出力数より少ない場 合は, 入力の自由度の方が出力の自由度よりあ小さく, 一般に参照信号に追従するてとはできない。したがって， われわれが考えるべきは, 入力数が出力数よりも多い場 合である.

制御対象の入出力数が同じ場合, 参照信号に制御出力 が一致するときの状態や入力の定常值は一意に決まり, それらとの偏差系に最適レギュレータ理論を適用するこ とによって, 最適制御則が得られる. しかし, 入力数が 出力数より多い場合, 状態や入力の定常值は一意淀ま らない. このとき, たとえば, 定常值として初期值に近 いものを選べば，応答は速く，制御対象の動きは小さく て済むことが期待できるであろう，その自由度は，何ら かの意味で, 最適な応答を実現するように決めるべきで

* 原稿受付 1993. 2. 5 .

** 神戸大学 工学部 Faculty of Engineering, Kobe University; Rokkodai-cho 1, Nada-ku, Kobe 657, Japan

*** 神戸大学 工学部 (現在, 三菱電機 (侏)

Faculty of Engineering, Kobe University ; ditto

Key Words : nonsquare plant, tracking system, servosystem, optimal regulator theory, step reference signal.
ある.

本論文では，乙のような観点に立って，制御対象の入 出力数が異なる場合に打ける最適追従系の設計法を提案 し，その拡張として，積分補償を加えた積分型最適サー ボ系, 2 自由度積分型最適サーボ系の設計法を与える.

なお，参考文献 1)では，入力の定常值を小さく選ぶこ とが提案されている，それに対して本論文では，偏差系 に対して定義された 2 次形式評価関数が最小になるよう に状態と入力の定常值を選ぶ.

\section{2. 最適追従系}

\section{1 最適追従系の構成}

対象とするシステムは, 状態方程式

$$
\begin{aligned}
& \dot{x}=A x+B u \\
& y=C x
\end{aligned}
$$

で表わされているとする. こてに， $x$ は $n$ 次元状態， $u$ は $m$ 次元操作入力, $y$ は $p$ 次元制御出力である. そし て, 入力数が出力数より多い, すなわち, $m>p$ とする. $A, B, C$ は適当な大きさの定数行列で, $B$ と $C$ はそれ ぞれ列フルランク，行フルランクをあつとし， $(A, B)$ は可安定対, $(C, A)$ は可検出対とする.

さらに, $(C, A, B)$ の組は入力可観測, すなわち,

†本論文では, 追従制御系のうち, 内部モデル原理 ${ }^{11)}$ 亿基づく サーボ補償器を含むものをサーボ系，含まないものを単に追 従系と呼ぶ. 


$$
\operatorname{rank}\left[\begin{array}{c}
C B \\
C A B \\
C A^{2} B \\
\vdots \\
C A^{n-1} B
\end{array}\right]=m
$$

が成り立つとする，乙の入力可観測性の定義は，参考文 献 2) に打ける出力可制御性と双対であり，どのような 方向のインパルス入力も出力に影響を与えることを意味 している. ての仮定を設ける理由は，後に与える最適制 御入力の一意性を保証するためである.（2）式の形から 分かるように, $(C, A)$ が可観測対ならば, $(C, A, B)$ の 組は入力可観測である. なお, 従来考えられてきた入力 数之出力数が等しい $m=p$ の場合には, 入力可観測性 は伝達関数行列 $C(s I-A)^{-1} B$ が正則であるととと等 価であり，下記の (3) 式の条件のもとで自動的に成立す るため, 陽に仮定される必要はなかった.

(1) 式のシステムに対して，ステップ状の $p$ 次元参照 信号 $r$ を考える。 そして, $r$ 亿追従するような制御系が 構成できるように,

$$
\operatorname{rank}\left[\begin{array}{cc}
A & B \\
C & 0
\end{array}\right]=n+p
$$

とする ${ }^{3)}$. このとき, 定常状態において出力 $y$ が定值 $r$ になるような状態と入力の值 $x_{\infty}, u_{\infty}$ は,

$$
\left[\begin{array}{ll}
A & B \\
C & 0
\end{array}\right]\left[\begin{array}{l}
x_{\infty} \\
u_{\infty}
\end{array}\right]=\left[\begin{array}{l}
0 \\
I
\end{array}\right] r
$$

を満たさなければならない. 状態と入力について定常值

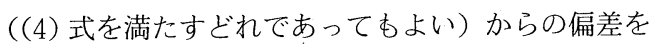

$$
\tilde{x}=x-x_{\infty}, \quad \tilde{u}=u-u_{\infty}
$$

と打くと, それらのふるまいは次の状態方程式に従う.

$$
\begin{aligned}
& \dot{\tilde{x}}=A \tilde{x}+B \tilde{u} \\
& e=-C \tilde{x}
\end{aligned}
$$

乙てに, $e$ は制御誤差

$$
e=r-y
$$

である.

制御出力 $y$ が参照入力 $r$ 亿追従するような制御系を 設計する場合, 制御誤差が速やかに0になり, 操作入力 屯速やかにその定常值となるように構成するのが良いで あろう。そ乙で, 制御䛊差と入力偏差の 2 次形式評価関 数

$$
J=\int_{0}^{\infty}\left(e^{\mathrm{T}} Q e+\tilde{u}^{\mathrm{T}} R \tilde{u}\right) d t
$$

を考える. ここで， $R$ と $Q$ は正定な行列とする. 積分
の下限である初期時刻 $t=0$ は参照信号 $r$ が変化した時 刻とし, 参照信号が変化するたびに最適に追従するよう な制御系を構成することを目指す。

評価関数 $J$ を(6) 式について最小とする操作入力偏 差 $\tilde{u}$ は,

$$
\tilde{u}=F_{0} \tilde{x}
$$

というフィードバック形式で実現できる4).ただし,

$$
F_{0}=-R^{-1} B^{\mathrm{T}} P
$$

である. ここで， $P$ はリカッチ方程式

$$
A^{\mathrm{T}} P+P A-P B R^{-1} B^{\mathrm{T}} P+C^{\mathrm{T}} Q C=0
$$

の半正定解である．そのような解の存在性と一意性は, これまでに述べた仮定によって保証されている4). そし て, (9) 式の制御則を(6) 式の偏差系にほどてして得ら れる閉ループ系は溸近安定で,

$$
\tilde{x} \rightarrow 0, \quad e \rightarrow 0 \quad(t \rightarrow \infty)
$$

となることが保証されている.

(9) 式のフィードバック則を, 操作入力 $u$ につて書 き直すと,

$$
u=F_{0} x+v_{\infty}
$$

となる。ただし，

$$
v_{\infty}=-F_{0} x_{\infty}+u_{\infty}
$$

である. ところで，(13) 式と（4）式より

$$
\left[\begin{array}{cc}
A+B F_{0} & B \\
C & 0
\end{array}\right]\left[\begin{array}{l}
x_{\infty} \\
v_{\infty}
\end{array}\right]=\left[\begin{array}{l}
0 \\
I
\end{array}\right] r
$$

が成立し，したがって，

$$
\begin{aligned}
& x_{\infty}=-\left(A+B F_{0}\right)^{-1} B v_{\infty} \\
& -C\left(A+B F_{0}\right)^{-1} B v_{\infty}=r
\end{aligned}
$$

の 2 式が導ける. ゆえに， $x_{\infty}$ と $u_{\infty}$ が (4) 式を満たすと とと $v_{\infty}$ が (16) 式を満たすととは等価である.（16）式 を満たす $v_{\infty}$ は, 入力数が出力数よりも多い場合, 一意 に定まらず，任意の $(m-p)$ 次元ベクトル $\eta$ を用いて,

$$
v_{\infty}=M^{-R} r+\Gamma \eta
$$

と表わせる.ただし，

$$
M=-C\left(A+B F_{0}\right)^{-1} B
$$

であり, $M^{-R}$ は (3) 式の仮定のあとで行フルランク $p$ をあつ $M$ の右逆行列, $\Gamma$ は $\left(I-M^{-R} M\right)$ の独立な $(m-p)$ 本の列を集めたあのである.よって，(17）式を (12) 式代入すると, 操作入力 $u$ は

$$
u=F_{0} x+M^{-R} r+\Gamma \eta
$$

となる. 乙の制御則の中の $\eta$ を任意に設定してあ, 閉 
ループ系か漸近安定であるととは保証されており，

$$
x \rightarrow x_{\infty}, \quad u \rightarrow u_{\infty} \quad(t \rightarrow \infty)
$$

したがって

$$
y \rightarrow r \quad(t \rightarrow \infty)
$$

となる。

それでは， $\eta$ をどのような值に設定するのがよいか考 えよう。そのために，(19）式の制御則によって得られ る (8) 式の評価関数の最小值

$$
\min _{\tilde{u}} J=\tilde{x}_{0}^{\mathrm{T}} P \tilde{x}_{0}
$$

を考える. ここに， $\tilde{x}_{0}$ は $\tilde{x}$ の初期值であり， $x$ の初期値 を $x_{0}$ とすると

$$
\tilde{x}_{0}=x_{0}-x_{\infty}
$$

である。また，(15）式に（17）式に代入すると,

$$
x_{\infty}=\Psi M^{-R} r+\Psi \Gamma \eta
$$

を得る。ただし

$$
\Psi=-\left(A+B F_{0}\right)^{-1} B
$$

である.したがって，(20) 式は

$$
\begin{aligned}
\min _{\tilde{u}} J= & \left(x_{0}-\Psi M^{-R} r-\Psi \Gamma \eta\right)^{\mathrm{T}} \\
& \times P\left(x_{0}-\Psi M^{-R} r-\Psi \Gamma \eta\right)
\end{aligned}
$$

と表わせる. そこで， $\eta$ は任意に選ぶことができるので， $\min _{\tilde{u}} J$ を最小化するととを考える.

さて, 制御対象の $(C, A, B)$ の組が入力可観測である という仮定より， $\Psi^{\mathrm{T}} P \Psi$ は正則であることを示すとと ができる (付録 1). したがって， $\Gamma^{\mathrm{T}} \Psi^{\mathrm{T}} P \Psi \Gamma$ あ正則で あり, $\min _{\tilde{u}} J$ を最小にする $\eta$ は

$$
\eta=\left(\Gamma^{\mathrm{T}} \Psi^{\mathrm{T}} P \Psi \Gamma\right)^{-1} \Gamma^{\mathrm{T}} \Psi^{\mathrm{T}} P\left(x_{0}-\Psi M^{-R} r\right)
$$

であることを示すことができる（付録 2)，そして，その 最小值は

$$
\begin{aligned}
\min _{\eta} \min _{\tilde{u}} J= & \left(x_{0}-\Psi M^{-R} r\right)^{\mathrm{T}} \\
& \times\left[P-P \Psi \Gamma\left(\Gamma^{\mathrm{T}} \Psi^{\mathrm{T}} P \Psi \Gamma\right)^{-1} \Gamma^{\mathrm{T}} \Psi^{\mathrm{T}} P\right] \\
& \times\left(x_{0}-\Psi M^{-R} r\right)
\end{aligned}
$$

である。乙うして決められた（25）式の $\eta$ を(19) 式に 代入して，最適制御則として,

$$
u=F_{0} x+H_{0} r+K_{0} x_{0}
$$

を得る.ただし，

$$
\begin{aligned}
& H_{0}=M^{-R}-K_{0} \Psi M^{-R} \\
& K_{0}=\Gamma\left(\Gamma^{\mathrm{T}} \Psi^{\mathrm{T}} P \Psi \Gamma\right)^{-1} \Gamma^{\mathrm{T}} \Psi^{\mathrm{T}} P
\end{aligned}
$$

である．乙れらは $M$ の右逆行列 $M^{-R},\left(I-M^{-R} M\right)$ の独立な列の選び方に依存せずに一意に決まる（付録 3 ).

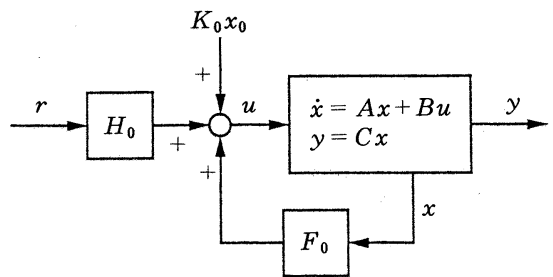

Fig. 1 Optimal tracking system

（27）式の制御則を（1）式の制御対象にほどこすと, その制御系は Fig.1 のようになる. 最適追従系は, 状 態フィードバックと参照信号からのフィードフォワード に加え, 初期状態によって決まる定数項から構成される. この制御則をほどこすととによって，実際，状態の定常 值 $x_{\infty}$ は (22) 式に（25）式を代入したものになる.

\section{2 最適追従系の特徵}

入出力数が同じ場合, フィードフォワードゲイン $H_{0}$ は，状態フィードバック系の部分の定常ゲインの逆行列 となって抢り, 参照信号から制御出力までの定常ゲイン が単位行列 $I$ になる5). これは追従系があつべき基本的 性質である．本論文で設計された制御系においても参照 信号 $r$ から制御出力 $y$ までの定常ゲインは,

$$
-C\left(A+B F_{0}\right)^{-1} B H_{0}=I
$$

である.乙れは (28) 式と, $M \Gamma=0$ であるとよより明 らかである。つまり，フィードフォワードゲイン $H_{0}$ は 状態フィードバック系部の定常ゲインの右逆行列（の一 つ）になっている.

また，同様に初期状態の項 $x_{0}$ から制御出力への定常 ゲインは,

$$
-C\left(A+B F_{0}\right)^{-1} B K_{0}=0
$$

である（30）式と（31）式を合わせて考えると，(27）式 の最適制御則に打ける定值入力 $K_{0} x_{0}$ は, 追従の過渡状 態のときにのみ効果が現れ，制御系の定常状態に扔いて は，制御出力に影響を与えていないてとがわかる．定值 入力 $K_{0} x_{0}$ は最適性の追求の結果現れた項なので，追従 の過渡状態でのみ効果があるあのであり，過渡応答を良 くするためにあると解釈できる.

なお，参照信号が変化した場合，一般の状況を考える と定值入力も変えなければならないが，参照信号の变化 が, システムが定常状態に落ちついている状況のみで起 こると仮定すれば，定值入力は必要はない，つまり，

$$
u=F_{0} x+H_{0} r
$$

が最適制御則となる.乙れは以下のように示すととがで きる。

（32）式の制御則をほどこしたとき，定常状態では 


$$
u_{\infty}=F_{0} x_{\infty}+H_{0} r
$$

である.これは，

$$
v_{\infty}=H_{0} r
$$

であるととを意味し，したがって，(15）式より

$$
x_{\infty}=\Psi H_{0} r
$$

である.（29）式より $K_{0} \Psi K_{0} \Psi=K_{0} \Psi$ が成立するてと を使うと,（28）式より

$$
K_{0} \Psi H_{0}=0
$$

であるととがいえるから

$$
K_{0} x_{\infty}=0
$$

が成立する，参照信号が変化したとき，新たな制御にお いて, これは

$$
K_{0} x_{0}=0
$$

を意味する，したがって，最適入力に定值入力は必要な い.

\section{3. 積分型最適サーボ系}

モデル化䛊差や制御対象のあいまいさ，定值外乱に対 処するためには, 内部モデル原理により, 追従誤差 $e$ の 積分補償が必要である ${ }^{3)}$ 。通常，それはFig. 2 の拡大系 の形で導入される. てれを状態方程式で表わすと,

$$
\begin{aligned}
{\left[\begin{array}{c}
\dot{x} \\
\dot{w}
\end{array}\right] } & =\left[\begin{array}{cc}
A & 0 \\
-C & 0
\end{array}\right]\left[\begin{array}{l}
x \\
w
\end{array}\right]+\left[\begin{array}{l}
B \\
0
\end{array}\right] u+\left[\begin{array}{l}
0 \\
I
\end{array}\right] r \\
y & =\left[\begin{array}{ll}
C & 0
\end{array}\right]\left[\begin{array}{c}
x \\
w
\end{array}\right]
\end{aligned}
$$

と書ける. (4) 式より状態と操作入力の定常值 $x_{\infty}, u_{\infty}$ が

$$
\left[\begin{array}{cc}
A & 0 \\
-C & 0
\end{array}\right]\left[\begin{array}{c}
x_{\infty} \\
w_{\infty}
\end{array}\right]+\left[\begin{array}{c}
B \\
0
\end{array}\right] u_{\infty}+\left[\begin{array}{l}
0 \\
I
\end{array}\right] r=0
$$

を満たすととを使って, 偏差 $\tilde{x}, \tilde{u}$ について書くと

$$
\begin{aligned}
{\left[\begin{array}{c}
\dot{\tilde{x}} \\
\dot{\tilde{w}}
\end{array}\right] } & =\left[\begin{array}{cc}
A & 0 \\
-C & 0
\end{array}\right]\left[\begin{array}{c}
\tilde{x} \\
\tilde{w}
\end{array}\right]+\left[\begin{array}{c}
B \\
0
\end{array}\right] \tilde{u} \\
e & =\left[\begin{array}{ll}
-C & 0
\end{array}\right]\left[\begin{array}{c}
\tilde{x} \\
\tilde{w}
\end{array}\right]
\end{aligned}
$$

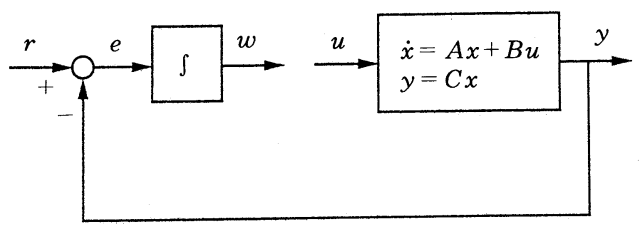

Fig. 2 Augmented system
を得る. ここに, $w_{\infty}$ は $w$ の定常值, $\tilde{w}$ は偏差

$$
\tilde{w}=w-w_{\infty}
$$

である. この偏差系を安定化することによってサーボ系 が得られる.

ここで注意すべきことは, 状態と入力の定常值 $x_{\infty}, u_{\infty}$ は一意ではなく，また $w$ の定常值 $w_{\infty}$ はまだ決まって いないてとである. 制御出力 $y$ が参照信号 $r$ に一致し たとき, 制御誤差 $e$ は 0 であるから, その積分である $w$ の定常值 $w_{\infty}$ が存在するてとは確かである. 以下では, ある評価関数を最小にする $x_{\infty}, u_{\infty}, w_{\infty}$ の值を求め, そ れらを実現する制御則を提案する.

その評価関数として，(8) 式の $J$ に $w$ 偏差 $\tilde{w}$ の 2 次形式を加えた

$$
J_{a}=\int_{0}^{\infty}\left(e^{\mathrm{T}} Q_{a 1} e+\tilde{w}^{\mathrm{T}} Q_{a 2} \tilde{w}+\tilde{u}^{\mathrm{T}} R_{a} \tilde{u}\right) d t
$$

を考える. 乙てに， $Q_{a 1}, Q_{a 2}, R$ はすべて正定な行列と する. $Q_{a 2}$ を正定として $\tilde{w}^{\mathrm{T}} Q_{a 2} \tilde{w}$ の項を組み入れたの は，そうしなければ積分補償の効果を制御に反映するこ とができないからである．乙の評価関数を(41) 式に関 して最小とする入力偏差 $\tilde{u}$ は，

$$
\tilde{u}=-R_{a}^{-1}\left[\begin{array}{ll}
B^{\mathrm{T}} & 0
\end{array}\right]\left[\begin{array}{cc}
P_{11} & P_{12} \\
P_{12}^{\mathrm{T}} & P_{22}
\end{array}\right]\left[\begin{array}{c}
\tilde{x} \\
\tilde{w}
\end{array}\right]
$$

というフィードバック形式で実現できる. こてに,

$$
\left[\begin{array}{ll}
P_{11} & P_{12} \\
P_{12}^{\mathrm{T}} & P_{22}
\end{array}\right]
$$

はリカッチ方程式

$$
\begin{aligned}
& {\left[\begin{array}{cc}
A^{\mathrm{T}} & -\mathrm{C}^{\mathrm{T}} \\
0 & 0
\end{array}\right]\left[\begin{array}{ll}
P_{11} & P_{12} \\
P_{12}^{\mathrm{T}} & P_{22}
\end{array}\right]+\left[\begin{array}{cc}
P_{11} & P_{12} \\
P_{12}^{\mathrm{T}} & P_{22}
\end{array}\right]\left[\begin{array}{cc}
A & 0 \\
-C & 0
\end{array}\right]} \\
& -\left[\begin{array}{ll}
P_{11} & P_{12} \\
P_{12}^{\mathrm{T}} & P_{22}
\end{array}\right]\left[\begin{array}{c}
B \\
0
\end{array}\right] R_{a}^{-1}\left[\begin{array}{ll}
B^{\mathrm{T}} & 0
\end{array}\right]\left[\begin{array}{cc}
P_{11} & P_{12} \\
P_{12}^{\mathrm{T}} & P_{22}
\end{array}\right] \\
& +\left[\begin{array}{cc}
C^{\mathrm{T}} Q_{a 1} C & 0 \\
0 & Q_{a 2}
\end{array}\right]=0
\end{aligned}
$$

の半正定解である. そのような解の存在性と一意性は, てれまでに述べた仮定によって保証されている，そして， $P_{22}$ は正則である ${ }^{6)}$. 得られた (44) 式の制御則を (41) 式の偏差系にほどしして得られる閉ループ系は漸近安定 で,

$$
\tilde{x} \rightarrow 0, \tilde{w} \rightarrow 0, \quad e \rightarrow 0 \quad(t \rightarrow \infty)
$$

となるととあ保証されている.

(44) 式のフィードバック則を入力 $u$ について書てう.

$$
u=F_{a} x+G_{a} w-G_{a} w_{\infty}+v_{a \infty}
$$


ただし，

$$
\begin{aligned}
F_{a} & =-R_{a}^{-1} B^{\mathrm{T}} P_{11}, G_{a}=-R_{a}^{-1} B^{\mathrm{T}} P_{12} \\
v_{a_{\infty}} & =-F_{a} x_{\infty}+u_{\infty}
\end{aligned}
$$

と抢いた，乙てで（15）式より（16）式が導かれたよう k

$$
-C\left(A+B F_{a}\right)^{-1} B v_{a \infty}=r
$$

が成立するととを用いると，

$$
M_{a}=-C\left(A+B F_{a}\right)^{-1} B
$$

の任意の右逆行列 $M_{a}^{-R}$ を用いて

$$
v_{a \infty}=M_{a}^{-R} r+\Gamma_{a} \eta_{a}
$$

と表わすことができる．ただし， $M_{a}$ は (3) 式の仮定の あとで行フルランク $p$ をあち, $\Gamma_{a}$ は $\left(I-M_{a}^{-R} M_{a}\right)$ の 独立な $(m-p)$ 本の列を集めたものである。 また， $\eta_{a}$ は $(m-p)$ 次元のベクトルで, $v_{a_{\infty}}$ があつ自由度を表わ している．以上より，(47）式の制御則は

$$
u=F_{a} x+G_{a} w-G_{a} w_{\infty}+M_{a}^{-R} r+\Gamma_{a} \eta_{a}
$$

と書き直すことができる.

それでは， $\eta_{a}$ と $w_{\infty}$ をどのような值に設定するのが 良いか考えよう。そのために，(53）式によって得ら机る (43) 式の評価関数の最小値

$$
\min _{\tilde{u}} J_{a}=\left[\begin{array}{ll}
\tilde{x}^{\mathrm{T}} & \tilde{w}_{0}^{\mathrm{T}}
\end{array}\right]\left[\begin{array}{cc}
P_{11} & P_{12} \\
P_{12}^{\mathrm{T}} & P_{22}
\end{array}\right]\left[\begin{array}{c}
\tilde{x}_{0} \\
\tilde{w}_{0}
\end{array}\right]
$$

を考える．乙こに， $\tilde{w}_{0}$ は $\tilde{w}$ の初期値である。つまり, $w$ の初期値を $w_{0}$ とすると,

$$
\tilde{w}_{0}=w_{0}-w_{\infty}
$$

である．参考文献 6) にあるように，まず最初に $w_{\infty} に$ ついて（54）式を最小化する，その結果，

$$
w_{\infty}=w_{0}+P_{22}^{-1} P_{12}^{\mathrm{T}}\left(x_{0}-x_{\infty}\right)
$$

のとき，最小值

$$
\min _{w \infty} \min _{\tilde{u}} J_{a}=\tilde{x}_{0}^{\mathrm{T}} \hat{P} \tilde{x}_{0}
$$

を得る。ただし，

$$
\hat{P}=P_{11}-P_{12} P_{22}^{-1} P_{12}^{\mathrm{T}}
$$

である.

つぎに,

$$
\Psi_{a}=-\left(A+B F_{a}\right)^{-1} B
$$

と招き， $x_{\infty}$ が (22) 式と同様に

$$
\begin{aligned}
x_{\infty} & =\Psi_{a} v_{a_{\infty}} \\
& =\Psi_{a} M_{a}^{-R} r+\Psi_{a} \Gamma_{a} \eta_{a}
\end{aligned}
$$

と表わせることを用いて，(57) 式の評価関数值

$$
\begin{aligned}
\tilde{x}_{0}^{\mathrm{T}} \hat{P} \tilde{x}_{0}= & \left(x_{0}-\Psi_{a} M_{a}^{-R} r-\Psi_{a} \Gamma_{a} \eta_{a}\right)^{\mathrm{T}} \\
& \times \hat{P}\left(x_{0}-\Psi_{a} M_{a}^{-R} r-\Psi_{a} \Gamma_{a} \eta_{a}\right)
\end{aligned}
$$

をさらに小さくする．制御対象の $(C, A, B)$ の組が入力 可観測であるという仮定から, $\Psi_{a}^{\mathrm{T}} \hat{P} \Psi_{a}$ の正則性を示す ことができる(付録 4). したがって, $\Gamma_{a}^{\mathrm{T}} \Psi_{a}^{\mathrm{T}} \hat{P} \Psi_{a} \Gamma_{a}$ あ 正則であるから，(24）式を最小化したように,

$$
\eta_{a}=\left(\Gamma_{a}^{\mathrm{T}} \Psi_{a}^{\mathrm{T}} \hat{P} \Psi_{a} \Gamma_{a}\right)^{-1} \Gamma_{a}^{\mathrm{T}} \Psi_{a}^{\mathrm{T}} \hat{P}\left(x_{0}-\Psi_{a} M_{a}^{-R} r\right)
$$

と選ぶと,

$$
\begin{aligned}
\min _{\eta_{a}} & \min _{w \infty} \min _{\tilde{u}} J_{a} \\
= & \left(x_{0}-\Psi_{a} M_{a}^{-R} r\right)^{\mathrm{T}} \\
& \times\left[\hat{P}-\hat{P} \Psi_{a} \Gamma_{a}\left(\Gamma_{a}^{\mathrm{T}} \Psi_{a}^{\mathrm{T}} \hat{P} \Psi_{a} \Gamma_{a}\right)^{-1} \Gamma_{a}^{\mathrm{T}} \Psi_{a}^{\mathrm{T}} \hat{P}\right] \\
& \times\left(x_{0}-\Psi_{a} M_{a}^{-R} r\right)
\end{aligned}
$$

を得る。

以上より，(60) 式の $x_{\infty}$ を用いながら $w_{\infty}$ を(56) 式 のように, $\eta_{a}$ を(62) 式のように設定すると, 評価関数 $J_{a}$ を最小にできることがわかった。 これらを(53) 式に 代入し整理すると, 最適制御則として,

$$
u=F_{a} x+G_{a} w+H_{a} r-G_{a} w_{0}+K_{a} x_{0}
$$

を得る。ただし，

$$
\begin{aligned}
H_{a}= & M_{a}^{-R}-K_{a} \Psi_{a} M_{a}^{-R} \\
K_{a}= & \Gamma_{a}\left(\Gamma_{a}^{\mathrm{T}} \Psi_{a}^{\mathrm{T}} \hat{P} \Psi_{a} \Gamma_{a}\right)^{-1} \Gamma_{a}^{\mathrm{T}} \Psi_{a}^{\mathrm{T}} \hat{P}-G_{a} P_{22}^{-1} P_{12}^{\mathrm{T}} \\
& \times\left[I-\Psi_{a} \Gamma_{a}\left(\Gamma_{a}^{\mathrm{T}} \Psi_{a}^{\mathrm{T}} \hat{P} \Psi_{a} \Gamma_{a}\right)^{-1} \Gamma_{a}^{\mathrm{T}} \Psi_{a}^{\mathrm{T}} \hat{P}\right]
\end{aligned}
$$

である. これらが, $M_{a}$ の右逆行列 $M_{a}^{-R}$ や $\left(I-M_{a}^{-R} M_{a}\right)$ の独立な列の選び方に依存しないととは，(28)，(29）式 の $H_{0}, K_{0}$ の一意性と同様汇示すととができる.

（64）式の制御則を(39) 式の拡大系にほどとすととに よって Fig. 3 の最適サーボ系を得る. この制御系に抺 いても，最適追従系の場合之同様，参照信号の変化はシ ステムが定常状態に落ちついている状況のみで起てると 仮定すれば，定值入力は必要はない，つまり，

$$
u=F_{a} x+G_{a} w+H_{a} r
$$

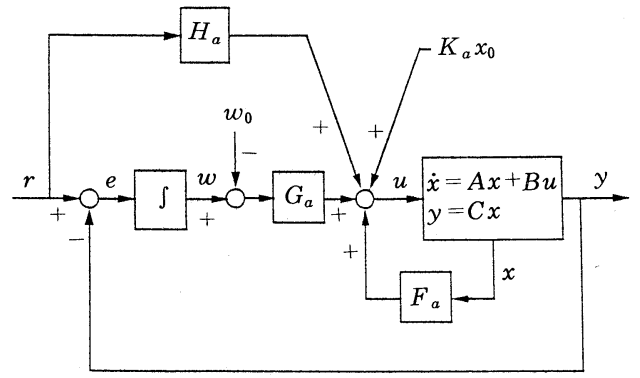

Fig. 3 Optimal servosystem 
が最適制御則となる（付録 5 ).

\section{2 自由度積分型最適サーボ系}

入出力数が同じシステムに対する積分型最適サーボ系 には，前節で述べたような拡大偏差系に最適レギュレー 夕理論を適用して得られるもののほかに，2 自由度構造 のあのが提案されている7。これは, 制御対象のモデル 化䛊差や外乱が存在しない場合には，積分補償は必要な いとの考えに基づくあのである. その構成法としては, ます参照信号への追従特性を積分補償なしの最適追従系 として設計し，つぎに制御対象のモデル化誤差や外乱に 対処するために, 積分補償を導入する.

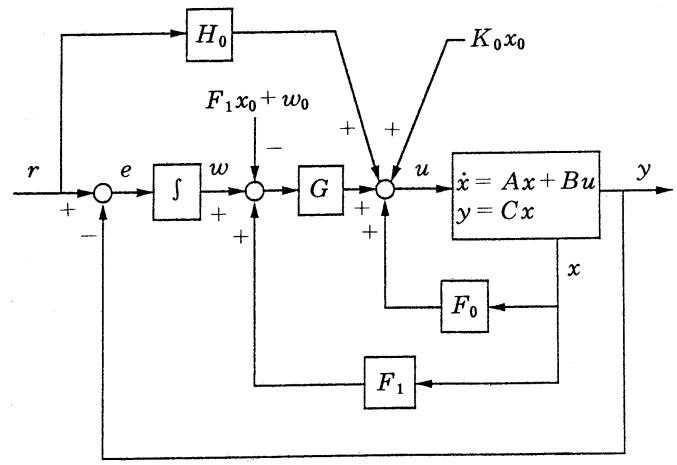

Fig. 4 Two-degree-of-freedom optimal servosystem

この設計法は入力数が出力数よりも多い制御対象にも, 2.1 で導いた最適追従系を用いてまったく同じように適 用できる. その結果, 得られる 2 自由度最適サーボ系は Fig.4 の構造をしている. ここに, $F_{0}, H_{0}, K_{0}$ は (10), (28)，(29）式で定義されたもの， $F_{1}$ は

$$
F_{1}=C\left(A+B F_{0}\right)^{-1}
$$

である. $G$ はこの制御系が安定となるように, $F_{1} B G$ す なわちー $M G$ が安定行列になるように選ばれる ${ }^{8)}$. 単な る安定化だけでなく，ある評価関数に対する最適性をあ 望む場合は，参考文献 7) と同様に

$$
G=R^{-1} M^{\mathrm{T}} W
$$

と選べばよい．ただし，W は任意の正定行列である.

なお，乙の 2 自由度最適サーボ系の場合も，参照信号 が定常状態でのみ变化する場合には, 初期状態に依存す る定值項 $K_{0} x_{0}, F_{1} x_{0}+w_{0}$ は必要ない. 乙れは 2.2 の議 論と参考文献 7) の結果より自明であろう.

\section{5. 数 值 例}

数值例により，2. で提案した最適追従系の有効性を 確認しよう. 対象システム (1) 式はつぎの行列で表わさ
れるあのとする.

$$
\begin{aligned}
A & =\left[\begin{array}{ccc}
0 & 1 & 0 \\
0 & 0 & 1 \\
4 & 2 & -3
\end{array}\right] \quad B=\left[\begin{array}{ll}
1 & 0 \\
0 & 0 \\
0 & 1
\end{array}\right] \\
C & =\left[\begin{array}{lll}
1 & 0 & 0
\end{array}\right]
\end{aligned}
$$

また，(8)式の評価関数の重みは,

$$
Q=1, \quad R=I
$$

とする. 乙のとき, 最適制御則 (27) 式の $F_{0}, H_{0}, K_{0}$ は つぎのように計算される.

$$
\begin{aligned}
F_{0} & =\left[\begin{array}{lll}
-2.5006 & -3.0605 & -0.7218 \\
-0.7218 & -1.1314 & -0.2775
\end{array}\right] \\
H_{0} & =\left[\begin{array}{c}
1.1416 \\
-2.7053
\end{array}\right] \\
K_{0} & =\left[\begin{array}{ccc}
1.3590 & 2.0605 & 0.5024 \\
-0.5729 & -0.8686 & -0.2118
\end{array}\right]
\end{aligned}
$$

まず，定值項 $K_{0} x_{0}$ が過渡応答をよくすることを確か めるために，最適制御則 (27) 式とそれから $K_{0} x_{0}$ を除 いた場合を比較しよう. 参照信号 $r$ を

$$
r= \begin{cases}1, & t \geq 0 \\ 0, & t<0\end{cases}
$$

初期状態を

$$
x_{0}=\left[\begin{array}{lll}
-0.1 & 0.5 & 1.0
\end{array}\right]^{\mathrm{T}}
$$

としてシミュレーションした結果を Fig. 5 に示す. 乙 の結果より, $K_{0} x_{0}$ が, 参照信号へのすばやい追従に効 果があることがわかる.

つぎに，乙の最適追従系と，参考文献 1) の方法で設 計した追従系を比較しよう. 参考文献 1) では, 状態フィ 一ドバックゲイン $F_{0}$ は本論文のものと等しく, 参照信 号からのフィードフォワードゲイン $H_{0}$ は入力の定常値 が小さくなるように決めることを提案している. この方 法によれば, $H_{0}$ は

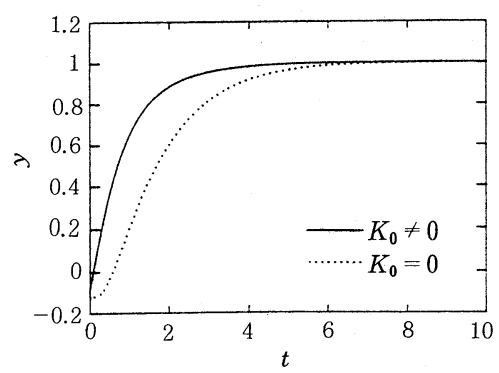

Fig. 5 Step responses of optimal tracking systems (nonzero initial condition) 


$$
H_{0}=\left[\begin{array}{l}
-0.7961 \\
-1.8884
\end{array}\right]
$$

と計算できる. $K_{0}$ は考えられていない，そてで，初期 状態を $x_{0}=0$ とし, 上の最適追従系亡参考文献 1) の追 従系を比較した結果を Fig. 6, Fig. 7 に与える. Fig. 6 は (73) 式の参照信号に対する出力の応答, Fig. 7 はそ のときの入力のふるまいである. この結果によると, 参 考文献 1) の制御則では, 入力の定常值は小さいものの, 出力に逆応答を生じている. それに対し 2. で提案した 制御則では，（8）式の評価関数の最小化を達成している ため，良い追従特性を実現している.

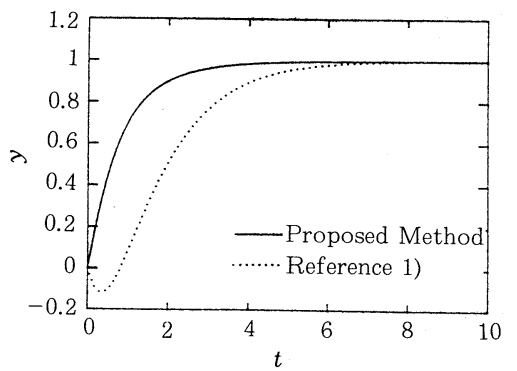

Fig. 6 Step responses of optimal tracking systems (zero initial condition)

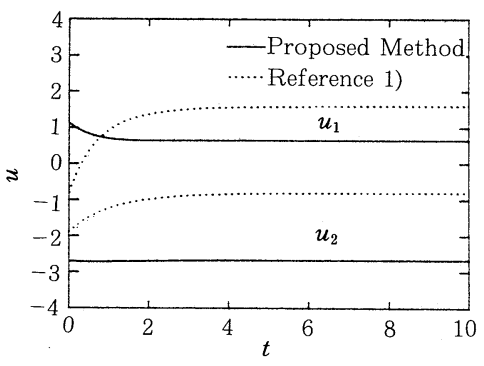

Fig. 7 Input behaviors of optimal tracking systems (zero initial condition)

同様に，3.の積分型最適サーボ系，4.の 2 自由度積 分型最適サーボ系の有効性を示すことができ, 本論文で 提案した状態と入力の定常值を設定する方法が効果的で あることが確認できる。

\section{6. おわりに}

本論文では，入力数が出力数よりも多い制御対象に対 して, 最適レギュレータ理論を応用した追従系, 積分型 サーボ系, 2 自由度積分型サーボ系の設計法を提案した。 このような制御対象の場合, 参照信号の值を出力に実現 する状態と入力の定常值は一意ではない. そのなかで, 2 次形式評価関数の意味で応答を良くするあのを選ぼう というのが，基本方針である．本論文では参照信号とし てステップ信号のみを考えたが，ランプ信号，正弦波信 号, 指数関数状信号の場合屯同様の考え方を適用して制
御系を設計することができる.

\section{参 考 文 献}

1) 朴, 鈴木, 藤井 : 多変数線形最適サーボ系の設計; 計測自 動制御学会論文集, Vol. 8, No. 5, pp. 568〜 575 (1972)

2) E. Kreindler and P. E. Sarachik: On the Concept of Controllability and Observability of Linear Systems ; IEEE Trans. Automatic Control, Vol. AC-9, No. 4, pp. 129 136 (1964)

3) 古田, 原：サーボ技術と現代制御論；計測と制御, Vol. 19, No. 10, pp. 953 961 (1980)

4) 木村: 多変数制御系の理論と応用一I ; システムと制御, Vol. 22, No. 5, pp. 293 301 (1978)

5）池田：SICE セミナー現代制御理論（初級）テキスト，計 測自動制御学会, p. 72 (1992)

6) 池田, 須田: 積分型最適サーボ系の構成; 計測自動制御学 会論文集, Vol. 24, No. 1, pp. 40〜46 (1988)

7) 藤崎, 池田 : 2 自由度皘分型最適サーボ系の構成; 計測自 動制御学会論文集, Vol. 27, No. 8, pp. 907〜914 (1991)

8）萩原, 大谷, 荒木 : 2 自由度 LQI サーボ系の設計法; シス テム制御情報学会論文誌, Vol. 4, No. 12，pp. 501〜 510 (1991)

9) 近藤, 原, 古田: 安定余裕を考慮した 1 型サーボ系の一設計 法 ; 計測自動制御学会論文集, Vol. 22, No. 11, pp.1142 1148 (1986)

10) 児玉, 須田: システム制御のためのマトリクス理論, 計測 自動制御学会 (1978)

11) B. A. Francis and W. M. Wonham: The Internal Model Principle for Linear Multivariable Regulators; J. Appl. Math. Opt., Vol. 2, pp.170 194 (1975)

\section{付 録}

\section{付録 $1 \boldsymbol{\Psi}^{\mathrm{T}} \boldsymbol{P} \Psi$ の正則性の証明}

リカッチ方程式 (11) 式を変形すると, リアプノフ方 程式

$$
\left(A+B F_{0}\right)^{\mathrm{T}} P+P\left(A+B F_{0}\right)+F_{0}^{\mathrm{T}} R F_{0}+C^{\mathrm{T}} Q C=0
$$

が得られ，てれより $P$ は

$$
P=\int_{0}^{\infty}\left\{e^{\left(A+B F_{0}\right) \tau}\right\}^{\mathrm{T}}\left(F_{0}^{\mathrm{T}} R F_{0}+C^{\mathrm{T}} Q C\right) e^{\left(A+B F_{0}\right) \tau} d \tau
$$

と表現できる.よって，

$$
\begin{aligned}
\Psi^{\mathrm{T}} P \Psi= & \int_{0}^{\infty}\left\{\left[\begin{array}{c}
Q^{\frac{1}{2}} C \\
R^{\frac{1}{2}} F_{0}
\end{array}\right] e^{\left(A+B F_{0}\right) \tau} \Psi\right\}^{\mathrm{T}} \\
& \times\left[\begin{array}{c}
Q^{\frac{1}{2}} C \\
R^{\frac{1}{2}} F_{0}
\end{array}\right] e^{\left(A+B F_{0}\right) \tau} \Psi d \tau
\end{aligned}
$$

である.これが正定行列であることと

$$
\left(\left[\begin{array}{c}
Q^{\frac{1}{2}} C \\
R^{\frac{1}{2}} F_{0}
\end{array}\right], A+B F_{0}, \Psi\right)
$$

の組が入力可観測であることは等価である ${ }^{2)}$.さて, 行 の付加や基本行変換 ${ }^{10)}$ を適当に行い，ヶーリー・八ミ ルトンの定理を用いれば, 


$$
\operatorname{rank}\left[\begin{array}{l}
C B \\
C A B \\
C A^{2} B \\
\vdots \\
C A^{n-1} B
\end{array}\right] \leq \operatorname{rank}\left[\begin{array}{c}
{\left[\begin{array}{c}
Q^{\frac{1}{2}} C \\
R^{\frac{1}{2}} F_{0}
\end{array}\right] B} \\
{\left[\begin{array}{c}
Q^{\frac{1}{2}} C \\
R^{\frac{1}{2}} F_{0}
\end{array}\right] A B} \\
{\left[\begin{array}{c}
Q^{\frac{1}{2}} C \\
R^{\frac{1}{2}} F_{0}
\end{array}\right] A^{2} B} \\
\vdots \\
{\left[\begin{array}{c}
Q^{\frac{1}{2}} C \\
R^{\frac{1}{2}} F_{0}
\end{array}\right] A^{n-1} B}
\end{array}\right]
$$

$$
\begin{aligned}
& {\left[\begin{array}{c}
Q^{\frac{1}{2}} C \\
R^{\frac{1}{2}} F_{0}
\end{array}\right] B} \\
& {\left[\begin{array}{c}
Q^{\frac{1}{2}} C \\
R^{\frac{1}{2}} F_{0}
\end{array}\right]\left(A+B F_{0}\right) B} \\
& =\operatorname{rank}\left[\begin{array}{c}
Q^{\frac{1}{2}} C \\
R^{\frac{1}{2}} F_{0}
\end{array}\right]\left(A+B F_{0}\right)^{2} B \\
& \left.\left[\begin{array}{c}
Q^{\frac{1}{2}} C \\
R^{\frac{1}{2}} F_{0}
\end{array}\right]\left(A+B F_{0}\right)^{n-1} B\right]
\end{aligned}
$$$$
\operatorname{rank}\left[\begin{array}{l}
{\left[\begin{array}{c}
Q^{\frac{1}{2}} C \\
R^{\frac{1}{2}} F_{0}
\end{array}\right]\left(A+B F_{0}\right)^{-1} B} \\
{\left[\begin{array}{c}
Q^{\frac{1}{2}} C \\
R^{\frac{1}{2}} F_{0}
\end{array}\right] B} \\
{\left[\begin{array}{c}
Q^{\frac{1}{2}} C \\
R^{\frac{1}{2}} F_{0}
\end{array}\right]\left(A+B F_{0}\right) B} \\
\vdots \\
{\left[\begin{array}{c}
Q^{\frac{1}{2}} C \\
R^{\frac{1}{2}} F_{0}
\end{array}\right]\left(A+B F_{0}\right)^{n-2} B}
\end{array}\right]
$$$$
=\operatorname{rank}\left[\begin{array}{c}
{\left[\begin{array}{c}
Q^{\frac{1}{2}} C \\
R^{\frac{1}{2}} F_{0}
\end{array}\right] \Psi} \\
{\left[\begin{array}{c}
Q^{\frac{1}{2}} C \\
R^{\frac{1}{2}} F_{0}
\end{array}\right]\left(A+B F_{0}\right) \Psi} \\
{\left[\begin{array}{c}
Q^{\frac{1}{2}} C \\
R^{\frac{1}{2}} F_{0}
\end{array}\right]\left(A+B F_{0}\right)^{2} \Psi} \\
\vdots \\
{\left[\begin{array}{c}
Q^{\frac{1}{2}} C \\
R^{\frac{1}{2}} F_{0}
\end{array}\right]\left(A+B F_{0}\right)^{n-1} \Psi}
\end{array}\right](\mathrm{A} 5)
$$

となる。乙れは, 対象システムの $(A, B, C)$ の組が入力 可観測であれば, (A4) 式の組あ入力可観測であるてと を示している. 以上より， $\Psi^{\mathrm{T}} P \Psi$ が正則であるてとが いえた.

\section{付録 2 (25) 式およひ (26) 式の導出}

（20）式に（21）式，(22）式を代入して整理すると, $\min _{\tilde{u}} J$

$$
\begin{aligned}
= & \left\{\eta-\left(\Gamma^{\mathrm{T}} \Psi^{\mathrm{T}} P \Psi \Gamma\right)^{-1} \Gamma^{\mathrm{T}} \Psi^{\mathrm{T}} P\left(x_{0}-\Psi M^{-R} r\right)\right\}^{\mathrm{T}} \\
& \times\left(\Gamma^{\mathrm{T}} \Psi^{\mathrm{T}} P \Psi \Gamma\right) \\
& \times\left\{\eta-\left(\Gamma^{\mathrm{T}} \Psi^{\mathrm{T}} P \Psi \Gamma\right)^{-1} \Gamma^{\mathrm{T}} \Psi^{\mathrm{T}} P\left(x_{0}-\Psi M^{-R} r\right)\right\} \\
& +J_{0}
\end{aligned}
$$

と書ける.ただし，

$$
\begin{aligned}
J_{0}= & \left(x_{0}-\Psi M^{-R} r\right)^{\mathrm{T}} \\
& \times\left\{P-P \Psi \Gamma\left(\Gamma^{\mathrm{T}} \Psi^{\mathrm{T}} P \Psi \Gamma\right)^{-1} \Gamma^{\mathrm{T}} \Psi^{\mathrm{T}} P\right\} \\
& \times\left(x_{0}-\Psi M^{-R} r\right)
\end{aligned}
$$

である. よって, $\min _{\tilde{u}} J$ を最小にするような $\eta$ は (25) 式，その最小値は(26) 式で与えられる.

付録 3 ゲイン $H, K$ の一意性

$M$ の任意の二つの右逆行列 $M_{1}^{-R}, M_{2}^{-R}$ の間には,

$$
\begin{aligned}
& M_{2}^{-R}=M_{1}^{-R}+\left(I-M_{1}^{-R} M\right) V \\
& I-M_{2}^{-R} M=\left(I-M_{1}^{-R} M\right) W
\end{aligned}
$$

の関係がある.乙こに, $V \in R^{m \times p}$ は適当な行列, $W \in$ $R^{m \times m}$ は適当な正則行列である. したがって, それらから 導か子る $\Gamma$ を $\Gamma_{1}, \Gamma_{2}$ と表わすと, 適当な $Y \in R^{(m-p) \times p}$ と正則な $T \in R^{(m-p) \times(m-p)}$ を用いて,

$$
M_{2}^{-R}=M_{1}^{-R}+\Gamma_{1} Y, \quad \Gamma_{2}=\Gamma_{1} T
$$

と表わせる.乙れらより，

$$
\begin{aligned}
\{I- & \left.\Gamma_{2}\left(\Gamma_{2}^{\mathrm{T}} \Psi^{\mathrm{T}} P \Psi \Gamma_{2}\right)^{-1} \Gamma_{2}^{\mathrm{T}} \Psi^{\mathrm{T}} P \Psi\right\} M_{2}^{-R} \\
= & \left\{I-\Gamma_{1}\left(\Gamma_{1}^{\mathrm{T}} \Psi^{\mathrm{T}} P \Psi \Gamma_{1}\right)^{-1} \Gamma_{1}^{\mathrm{T}} \Psi^{\mathrm{T}} P \Psi\right\} M_{1}^{-R} \Gamma_{2} \\
& \times\left(\Gamma_{2}^{\mathrm{T}} \Psi^{\mathrm{T}} P \Psi \Gamma_{2}\right)^{-1} \Gamma_{2}^{\mathrm{T}} \Psi^{\mathrm{T}} P \\
= & \Gamma_{1}\left(\Gamma_{1}^{\mathrm{T}} \Psi^{\mathrm{T}} P \Psi \Gamma_{1}\right)^{-1} \Gamma_{1}^{\mathrm{T}} \Psi^{\mathrm{T}} P
\end{aligned}
$$

が成立する. よって, $H, K$ は, $\Gamma, \Psi$ の選び方に依存 しない.

\section{付録 $4 \boldsymbol{\Psi}_{a}^{\mathrm{T}} \hat{\boldsymbol{P}} \Psi_{a}$ の正則性の証明}

リカッチ方程式 (45) 式より,

$\left(A+B F_{a}\right)^{\mathrm{T}} \hat{P}+\hat{P}\left(A+B F_{a}\right)+F_{a}^{\mathrm{T}} R F_{a}+C^{\mathrm{T}} Q_{a 1} C=0$

が成立する ${ }^{9)}$. したがって，付録 1 とまったく同様にし

て, $\Psi_{a}^{\mathrm{T}} \hat{P} \Psi_{a}$ が正則であるととがいえる. 
付録 $5(67)$ 式の制御則の最適性

（67）式の制御則をほどこしたとき，定常状態では

$$
u_{\infty}=F_{a} x_{\infty}+G_{a} w_{\infty}+H_{a} r
$$

が成立している，つまり，

$$
-v_{a \infty}+G_{a} w_{\infty}+H_{a} r=0
$$

である. 一方，(52）式と（60）式より

$$
\begin{aligned}
H_{a} r & =M_{a}^{-R} r-K_{a} \Psi_{a} M_{a}^{-R} r \\
& =v_{a \infty}-\Gamma_{a} \eta_{a}-K_{a} x_{\infty}+K_{a} \Psi_{a} \Gamma_{a} \eta_{a} \\
& =v_{a \infty}-K_{a} x_{\infty}
\end{aligned}
$$

がいえるから，結局，

$$
G_{a} w_{\infty}-K_{a} x_{\infty}=0
$$

が成立する。なお，(A15) 式の最後の等号は，(66) 式 より $K_{a} \Psi_{a} \Gamma_{a}=\Gamma_{a}$ がいえることによる. (A 16) 式は, 参照信号が変化したとき, 新たな制御において,

$$
G_{a} w_{0}-K_{a} x_{0}=0
$$

を意味する. したがって，(67）式に定值入力の項は必要 ない。 